\title{
ANÁLISE DE CRESCIMENTO EM HETERANTHERA RENIFORMIS, SOB DIFERENTES TEORES DE Ca, Mg E S ( $\left.{ }^{1}\right)$
}

\author{
VANESSA DAVID DOMINGOS $\left({ }^{2}\right)$; DAGOBERTOMARTINS $\left({ }^{4}\right)$; DIRCEU MAXIMINO FERNANDES $\left({ }^{4}\right)$; \\ NEUMARCIO VILANOVA DA COSTA $\left({ }^{2}\right)$; PAULO LOVO DE PASCHOA $\left({ }^{3}\right)$
}

\begin{abstract}
RESUMO
O objetivo deste trabalho foi estudar o crescimento, alocação de biomassa e teores de nutrientes em Heteranthera reniformis Ruiz \& Pav., sob o efeito de diferentes concentrações de Ca, Mg e S. As plantas foram cultivadas em vasos plásticos preenchidos com pedra rolada, em soluções nutritivas a $80 \%$ da concentração original de Sarruge, correspondente à solução-base. O experimento foi desenvolvido em delineamento experimental inteiramente casualizado, com quatro teores $(0 \%, 25 \%, 50 \%$ e $75 \%$ da solução base de $80 \%$ ) avaliados em $\mathrm{Ca}, \mathrm{Mg}$ e S, além da testemunha (solução-base), com quatro repetições no período de 35 dias em casa de vegetação. O aumento dos teores de Ca na solução propiciou uma redução significativa na área foliar. As maiores áreas foliares ocorreram em soluções a $25 \%$ de Ca e $50 \%$ de $\mathrm{Mg}$ e S. A maior proporção de biomassa seca está no caule, exceto a $25 \%$ de Ca $\left(40 \mathrm{mg} \mathrm{L}^{-1}\right)$ que propiciou maior área foliar e área foliar específica. Entre os teores de $\mathrm{Mg}$ na solução, as maiores biomassas foram observadas a $50 \%$ de $\mathrm{Mg}\left(19,2 \mathrm{mg} . \mathrm{L}^{-1}\right)$ e, para o S, não houve diferenças significativas, exceto a $0 \%$. A solução com $160 \mathrm{mg} \mathrm{L}^{-1}$ de Ca propiciou maior concentração de Ca na folha $\left(56,6 \mathrm{~g} \mathrm{~kg}^{-1}\right)$. Os teores de $\mathrm{Ca}, \mathrm{Mg}$ e $\mathrm{S}$ em solução corresponderam a um aumento proporcional na planta. Os teores de enxofre nas folhas e nos caules aumentaram com a concentração de $S$ na solução, enquanto o teor nas raízes reduziu nas concentrações entre 12,8 e $38,4 \mathrm{mg} \mathrm{L}^{-1}$.
\end{abstract}

Palavras-chave: planta aquática, planta daninha, nutrientes e biomassa.

\section{ABSTRACT \\ GROWTH ANALYSIS IN HETERANTHERA RENIFORMIS UNDER DIFFERENT CONTENTS OF Ca, Mg AND S}

The objective was to study the growth, biomass allocation and concentration of nutrients in Heteranthera reniformis Ruiz \& Pav. under the effect of different concentrations of $\mathrm{Ca}, \mathrm{Mg}$ and $\mathrm{S}$. The plants were cultivated in plastic pots fulfilled with rolled stone, in nutrient solutions of $80 \%$ of the original concentration of Sarruge. The experiment was carried out in a complete randomized design, with 4 contents $(0,25,50$ and $75 \%$ of the solution base ) evaluated in $\mathrm{Ca}, \mathrm{Mg}$ and S, plus the control $(100 \%$ of the solution base), with 4 replicates in the period of 35 days in greenhouse. The increase of contents of Ca produced significant reduction in the leaf area. The largest areas leaf occurred in solutions of $25 \%$ of Ca and $50 \%$ of $\mathrm{Mg}$ and S. The largest proportion of dry biomass was found in the stem, except with $25 \%$ of $\mathrm{Ca}_{\left(40 \mathrm{mg} \mathrm{L}^{-1}\right)}$ in solution that produced larger leaf area and larger specific leaf area. Among different $\mathrm{Mg}$ contents, larger biomasses were observed at $50 \%$ of $\mathrm{Mg}\left(19,2 \mathrm{mg} \mathrm{L}^{-1}\right)$ and, for $\mathrm{S}$, there were not significant differences, except at $0 \%$ of $S$ in solution. The solution with $160 \mathrm{mg} \cdot \mathrm{L}^{-1}$ of Ca produced the largest concentration of Ca in leaf $\left(56,6 \mathrm{~g} \mathrm{~kg}^{-1}\right)$. The contents of $\mathrm{Ca}, \mathrm{Mg}$ and $\mathrm{S}$ in solution corresponded to a proportional increase in the plant. The contents of sulfur in leaves and in stems increased with the concentration of $S$, whereas the content in roots reduced in the concentrations between 12,8 and $38,4 \mathrm{mg} \mathrm{L}^{-1}$.

Key words: Aquatic plant, weed, nutrients and biomass.

(1) Recebido para publicação em 16 de março de 2005 e aceito em 28 de abril de 2006.

( $\left.{ }^{2}\right)$ Faculdade de Ciências Agronômicas-UNESP, Caixa Postal 237, 18603-970 Botucatu (SP). Autora correspondente. E-mail: vanessadavid@fca.unesp.br

$\left(^{3}\right)$ Aluno de graduação de Engenharia Agronômica, FCA-UNESP, Botucatu (SP).

$\left({ }^{4}\right)$ Departamento de Agricultura, FCA-UNESP. 


\section{INTRODUÇÃO}

Heteranthera reniformis Ruiz \& Pav., considerada como planta daninha em áreas de arroz irrigado e canais de irrigação, possui elevado potencial de infestação (Ferrero, 1996; Vescovi et al., 1996; VASCONCELOS et al., 1999), porém os trabalhos relacionados à absorção de nutrientes e crescimento, ainda são escassos.

Planta perene e aquática da família Pontederiaceae, essa espécie possui alguns nomes populares como agriãozinho aquático, hortelã-dobrejo, pavoa, aguapé-mirim, dentre outros. Desenvolve-se, inicialmente, a partir da semente que germina apenas em solo saturado de água, após o que, ocorre o enraizamento. No entanto, quando aumenta o nível da água, desprende-se do solo e flutua. Possui como meio de reprodução predominante a propagação vegetativa, por meio da qual se originam grandes conjuntos de plantas, formando extensos tapetes flutuantes. O habitat mais propício pode ser tanto na água quanto em solos úmidos e origina-se de regiões de clima tropical e subtropical das Américas e África. No Brasil, observa-se ampla distribuição em quase todo o território (Kissmann e Groth, 1997).

Várias características morfológicas definem a habilidade de espécies competirem por recursos. A captação de luz na vegetação pode ser determinada pela distribuição da área foliar sobre o peso de folha que resulta em uma medida de área foliar total ou área foliar específica em $\mathrm{m}^{2} \mathrm{~g}^{-1}$ folha (SCHIPPERS e OlfF, 2000). $\mathrm{O}$ conhecimento dos teores de nutrientes em vários órgãos do vegetal permite inferir sobre as exigências metabólicas desenvolvidas em cada compartimento, fornecendo base para o entendimento dessas variações e suas implicações nas respostas dos vegetais no ecossistema (Mendes, 1996). A distribuição de nutrientes entre os diferentes tipos de células constituintes de diversos tecidos permite conhecer as funções metabólicas as quais desempenham (RAIJ, 1991; BergmanN, 1992; BenNetT, 1996).

Barrat-Segretain (2001) relata que, geralmente, plantas aquáticas submersas têm sistema radicular menor quando comparados às terrestres, correspondendo a aproximadamente $10 \%$ do total de biomassa da planta. Pode ser relacionado ao tipo de reprodução dessas espécies, definidas basicamente por propágulos vegetativos, justificando assim a alocação de fotoassimilados em biomassa de órgãos da parte aérea. A absorção de nutrientes em plantas aquáticas ocorre não apenas por raízes, mas também por folhas submersas.
As plantas aquáticas conferem autonomia ao ambiente aquático, pois representam a base da organização do sistema pela produção de biomassa que, ao se decompor, promove uma liberação maciça de nutrientes inorgânicos e matéria orgânica dissolvida. As taxas de liberação são influenciadas pela dinâmica populacional das plantas, pela sua mortalidade durante e após o crescimento e pelas condições ambientais (WETZEL, 1993).

Além desses fatores, o tipo de vegetação também influencia na decomposição, bem como na liberação de nutrientes e compostos orgânicos, sendo mais acelerada nas plantas aquáticas submersas e de folhas flutuantes quando comparada às emersas (WeTZEL, 1993).

Contudo, o crescimento excessivo dessas plantas tem causado sérios problemas como a redução na produção de peixes, esportes aquáticos, navegação, irrigação e produção de energia hidrelétrica (THOMAZ e BINI, 1998). O aumento populacional desordenado dessas plantas deve-se principalmente à falta de predadores e ao aumento do nível de eutrofização do ambiente (Esteves, 1998).

As pesquisas mais recentes relacionadas com o ambiente aquático têm explorado a contaminação por metais pesados, a eutrofização e a utilização de plantas aquáticas como biofiltros ou indicadores de poluição, dentre as quais se destaca o aguapé Eichhornia crassipes L. e Typha spp. na remoção e absorção de cobre, nitrogênio, fósforo e cálcio (NichOls e Buchan, 1997; Oliveira et al., 2001; Olivares et al., 2002; SAHA e JANA, 2003; So et al., 2003). Portanto, ainda não foram realizadas pesquisas com outros nutrientes como magnésio e enxofre.

Visto que tal espécie possui uma elevada capacidade de colonização em condições favoráveis de crescimento, torna-se necessário conhecer seu desenvolvimento para subsidiar medidas preventivas de controle. Assim, o objetivo foi estudar a distribuição de biomassa, crescimento e alocação de nutrientes nos órgãos da planta de $H$. reniformis sob diferentes teores de $\mathrm{Ca}, \mathrm{Mg}$ e $\mathrm{S}$ em solução nutritiva.

\section{MATERIAL E MÉTODOS}

O experimento foi instalado em casa de vegetação no Núcleo de Pesquisas Avançadas em Matologia (NUPAM), do Departamento de Produção Vegetal da FCA/UNESP, Campus de Botucatu (SP).

As mudas foram obtidas em um canal de drenagem na várzea localizado na Fazenda Edgardia, pertencente à UNESP, Campus de Botucatu. Foram 
selecionadas mudas com três folhas. Para o plantio foram utilizados vasos plásticos $(13,8 \times 28,3 \times 11,8 \mathrm{~cm}$ de largura, comprimento e altura respectivamente) de 4,5 litros, totalizando uma área de superfície aproximada de $0,04 \mathrm{~m}^{2}$, contendo 0,5 litros de pedras rolada lavadas com água destilada. Nesse substrato foi realizado o plantio de uma muda (lavada com água destilada) sendo adicionado 0,5 litros de solução nutritiva.

As soluções nutritivas foram mantidas com aeração constante através de um sistema de mangueiras e registros interligados a compressores de ar, sendo renovadas a cada três dias, bem como, lavado o substrato com água destilada. Os sais utilizados no preparo das soluções-estoque na concentração de $1 \mathrm{M}$ foram: $\mathrm{KH}_{2} \mathrm{PO}_{4}, \mathrm{KNO}_{3}, \mathrm{Ca}\left(\mathrm{NO}_{3}\right)_{2}$, $\mathrm{MgSO}_{4}, \mathrm{Kcl} \mathrm{CaCl}_{2}, \mathrm{NH}_{4} \mathrm{H}_{2} \mathrm{PO}_{4}, \mathrm{NH}_{4} \mathrm{NO}_{3},\left(\mathrm{NH}_{4}\right)_{2} \mathrm{SO}_{4} \mathrm{e}$ $\mathrm{Mg}\left(\mathrm{NO}_{3}\right)_{2}$. Para o preparo da solução de micronutrientes foram utilizados $\mathrm{H}_{3} \mathrm{BO}_{3}(2,86 \mathrm{~g})$, $\mathrm{MnCl}_{2} \cdot 4 \mathrm{H}_{2} \mathrm{O}(1,81 \mathrm{~g}), \mathrm{ZnCl}_{2}(0,10 \mathrm{~g}), \mathrm{CuCl}_{2}(0,04 \mathrm{~g})$, $\mathrm{H}_{2} \mathrm{MoO}_{4} \cdot \mathrm{H}_{2} \mathrm{O}(0,02 \mathrm{~g})$ sendo diluídos em água destilada e, em seguida, o volume completado para 1 litro em balão volumétrico. A solução de Fe-EDTA foi obtida através da dissolução de 26,2 g de EDTA dissódico (etileno diamino tetra acetato de sódico) e $24,0 \mathrm{~g}$ de $\mathrm{FeSO}_{4} \cdot 7 \mathrm{H}_{2} \mathrm{O}$ separadamente em água destilada, sendo depois misturados. A solução foi arejada com um compressor de ar no período de 12 horas, em seguida, submetida a um filtro de papel, sendo o volume completado para 1 litro em balão volumétrico, e armazenada em frasco de vidro escuro, tampado e acondicionado em câmara fria.

Antes da instalação do experimento foi realizado um ensaio para determinar a concentração de nutrientes da solução de SARruge (1975), mais próxima das concentrações adequadas para a espécie e utilizada como testemunha no experimento.

Nessa etapa prévia à instalação do estudo definitivo, seguindo métodos descritos anteriormente para seleção de mudas, plantio e manejo de experimento, foram utilizadas quatro diluições correspondentes a $20 \%, 40 \%, 60 \%, 80 \%$ e uma testemunha $100 \%$ da solução de Sarruge (1975) as quais foram padronizadas a pH 6,5 através da adição de $\mathrm{HCl}$ ou $\mathrm{NaOH}$. O delineamento experimental utilizado no experimento foi o inteiramente ao acaso, com seis tratamentos e quatro repetições, por um período de 32 dias. As variáveis analisadas foram: área foliar, área foliar especifica, número de folhas, massa seca (folha, caule, raiz e total).

Para manter as concentrações iniciais de nutrientes durante o intervalo de troca da solução, foram realizadas reposições do volume com água destilada, conforme a evaporação de cada vaso, através do nível marcado com grafite em uma plaqueta colada na lateral deste recipiente.
Os resultados permitiram a escolha da solução nutritiva a $80 \%$ da solução de Sarruge a qual propiciou condições próximas do nível ótimo à demanda nutricional da espécie, constituída por: $\mathrm{N}, \mathrm{P}, \mathrm{K}, \mathrm{Ca}, \mathrm{Mg}$ e $S$ correspondente às concentrações de 168,$0 ; 24,8$; 187,2; 160,0; 38,4 e 51,2 mg L-1 e Fe, B, Mn, Zn, Cu e Mo referente a $4 ; 0,4 ; 0,4 ; 0,04 ; 0,0016 ; 0,0008 \mathrm{mg} \mathrm{L}^{-1}$.

O estudo definitivo foi realizado durante 35 dias nas mesmas instalações, procedimentos de montagem e biometria do experimento anterior. $\mathrm{O}$ delineamento experimental utilizado foi o inteiramente ao acaso, com quatro concentrações $(0 \%, 25 \%, 50 \%$, $75 \%$ da solução-base) avaliadas em Ca, Mg e S (não utilizando combinações fatoriais), além da testemunha com quatro repetições. A concentração dos nutrientes analisados nas soluções variou entre diferentes teores de $\mathrm{Ca}\left(0 ; 40 ; 80 ; 120\right.$ e $\left.160 \mathrm{mg} \mathrm{l}^{-1}\right), \mathrm{Mg}(0 ; 9,6 ; 19,2$; 28,8 e 38,4 mg..$\left.^{-1}\right)$ e S $\left(0 ; 12,8 ; 25,6 ; 38,4\right.$ e 51,2 mg..$\left.^{-1}\right)$, sendo preservadas nessas soluções a concentração dos demais nutrientes com o balanceamento químico das concentrações dos nutrientes, realizado em planilhas no programa excel, em que foram calculados acréscimos ou reduções na quantidade adicionada das fontes de nutrientes. As soluções nutritivas foram renovadas a cada três dias sempre mantendo o $\mathrm{pH}$ 6,0, além de lavar substrato com água destilada.

A determinação dos nutrientes ( $\mathrm{Ca}, \mathrm{Mg}$ e $\mathrm{S}$ ), nas diferentes partes da planta, foi realizada no Laboratório de Relação Solo/Planta do Departamento de Produção Vegetal, da FCA-UNESP / Botucatu. Para a determinação dos teores de $\mathrm{P}$ e $\mathrm{K}$, o material vegetal foi digerido em uma mistura de ácido nitro-perclórico, sendo para o $\mathrm{N}$ submetido à digestão sulfúrica, seguindo o método proposto por Malavolta et al. (1989). O N das amostras foi determinado por titulometria (método proposto por MALAVolta et al., 1989), enquanto os outros macronutrientes foram determinados por espectrometria de plasma. Para os resultados de área foliar específica, utilizou-se a relação entre área foliar e a massa seca de folha, para obter valores em $\mathrm{m}^{2} \mathrm{~g}^{-1}$ folha.

Os resultados foram submetidos à análise de variância pelo teste $\mathrm{F}$ e a comparação de médias realizadas pelo teste $\mathrm{t}$ a $5 \%$ de probabilidade. Realizaram-se as análises de regressão com a média, utilizando o programa Jandel Sigma Stat 2.0, e apenas as regressões foram significativas.

\section{RESULTADOS E DISCUSSÃO}

Verificou-se na área foliar redução significativa com o aumento dos teores de Ca na solução conforme pôde ser observado na análise de regressão para os diferentes teores. 
O modelo que melhor se ajustou aos dados foi o linear $\left(R^{2}=0,90 ; p<0,01\right)$ (Figura 1). Verificouse a $25 \%$ de Ca que houve condições propícias para o desenvolvimento da área foliar, visto que nesse teor foi obtido o maior valor, correspondente a 807,6 cm² $^{2}$ em comparação aos demais tratamentos. Essa resposta pode estar relacionada à inibição competitiva com o magnésio que influencia diretamente a expansão foliar, em razão de sua função fotossintética como elemento estrutural da molécula de clorofila (MARSCHNER, 1986). Quanto aos resultados referentes à ausência de Ca não foi possível determinar a área foliar, pois as folhas já estavam em processo de decomposição. Esse sintoma caracteriza a deficiência de Ca devido à desintegração das paredes celulares que ocasiona a liberação do citoplasma e conseqüente colapso dos tecidos afetados (MARsCHNEr, 1986).

Para os teores de $\mathrm{Mg}$ e $\mathrm{S}$ as regressões não foram significativas, porém as maiores áreas foliares ocorreram em soluções a $50 \%$ de $\mathrm{Mg}$ e S (524,30 e $\left.516,15 \mathrm{~cm}^{2}\right)$, conforme as Figuras 2 e 3 . Verificou-se que a ausência de $\mathrm{Mg}$ propiciou sintomas de deficiência mais críticos em relação ao enxofre, resultando em menores valores de área foliar $(22,9$ $\mathrm{cm}^{2}$ ), que ressalta a importância vital desse nutriente no metabolismo da planta.

O potencial de cobertura da planta foi verificado na determinação da área foliar específica em que se observou uma tendência linear e decrescente com o aumento dos teores de cálcio $\left(R^{2}=0,80 ; p<0,05\right)$, Figura 4. Observou-se que a $40 \mathrm{mg} \mathrm{L}^{-1} \mathrm{de}$ Ca propiciou maior valor de cobertura foliar referente a $22 \mathrm{~m}^{2} \mathrm{~g}^{-1}$ folha. Para o $\mathrm{Mg}$ o melhor ajuste foi o linear e crescente com os teores de magnésio em uma amplitude de 3,4 a $6,4 \mathrm{~m}^{2} \mathrm{~g}^{-1}$ folha.

Quanto à alocação de biomassa em $H$. reniformis, verificou-se que a maior proporção está no caule, exceto a $25 \%$ de Ca $\left(40 \mathrm{mg} \mathrm{L}^{-1}\right)$ que propiciou maior área foliar bem como área foliar específica (Figuras 6, 7 e 8). Entretanto, a 100\% de Ca $\left(160 \mathrm{mg} \mathrm{L}^{-1}\right)$ houve maior produção de biomassa nas folhas, caules e raízes em relação aos demais teores pelo teste $\mathrm{t}(\mathrm{p}=0,05 \%)$. Entre os teores de $\mathrm{Mg}$, maiores biomassas foram observadas a $50 \%$ de $\mathrm{Mg}$ $\left(19,2 \mathrm{mg} \mathrm{L}^{-1}\right)$. Para o $\mathrm{S}$, não houve diferenças significativas, exceto a $0 \%$, com os menores valores em relação aos demais teores.

A amplitude de variação da proporção de raízes com o total de biomassa da planta foi maior entre os teores de $\mathrm{S}(3,2 \%-11,2 \%$ referente a 25,6 e 0 $\left.\mathrm{mg} \mathrm{L}^{-1}\right)$, em relação aos teores de Ca $(1,8 \%-6,8 \%$ referente a 40 e $\left.120 \mathrm{mg} \mathrm{L}^{-1}\right)$ e aos de $\mathrm{Mg}(4,4 \%-7,4 \%$ referente a 0 e $19,2 \mathrm{mg} \mathrm{L}^{-1}$ ). BARRAT-SEGRETAIN (2001) relata que, geralmente, plantas aquáticas submersas têm sistema radicular menor quando comparadas às terrestres, correspondendo a aproximadamente 10\% do total de biomassa da planta.

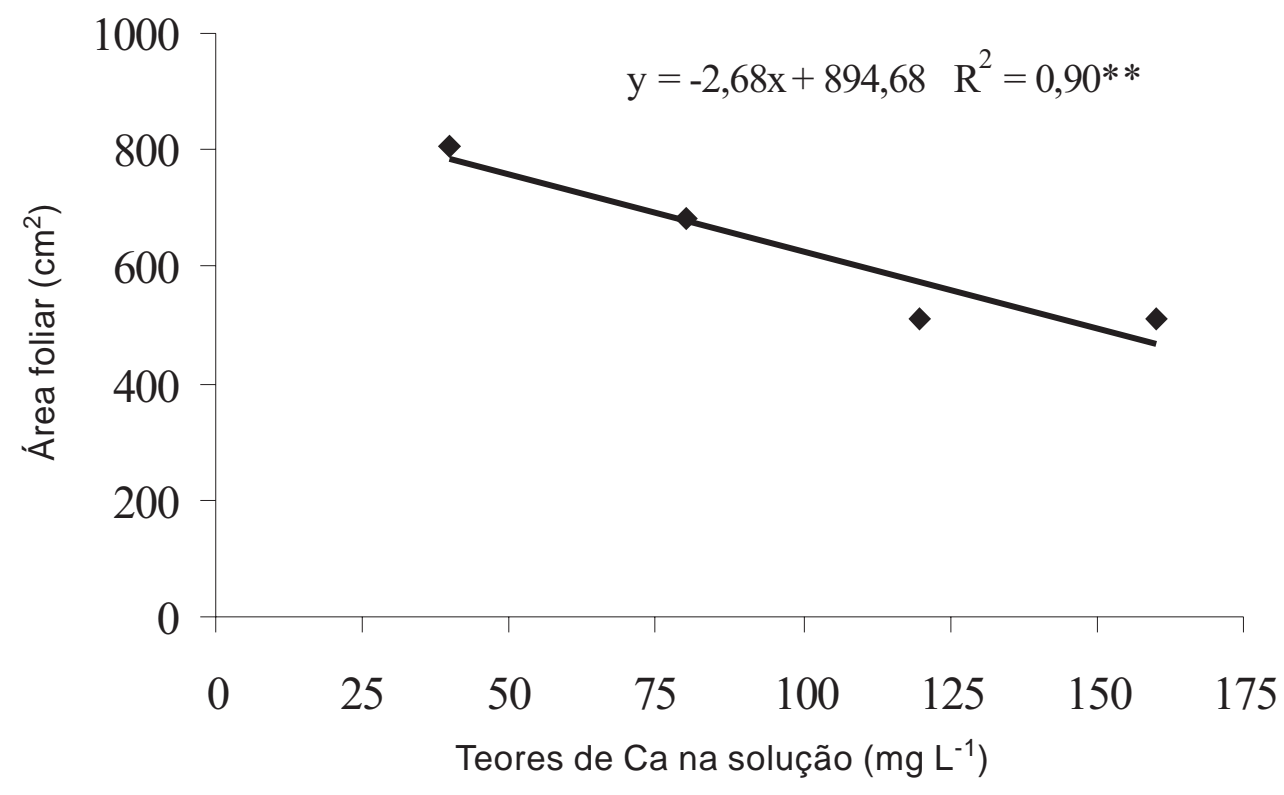

Figura 1. Área foliar de Heteranthera reniformis sob o efeito de diferentes teores de cálcio na solução nutritiva. Botucatu (SP), 2004. 


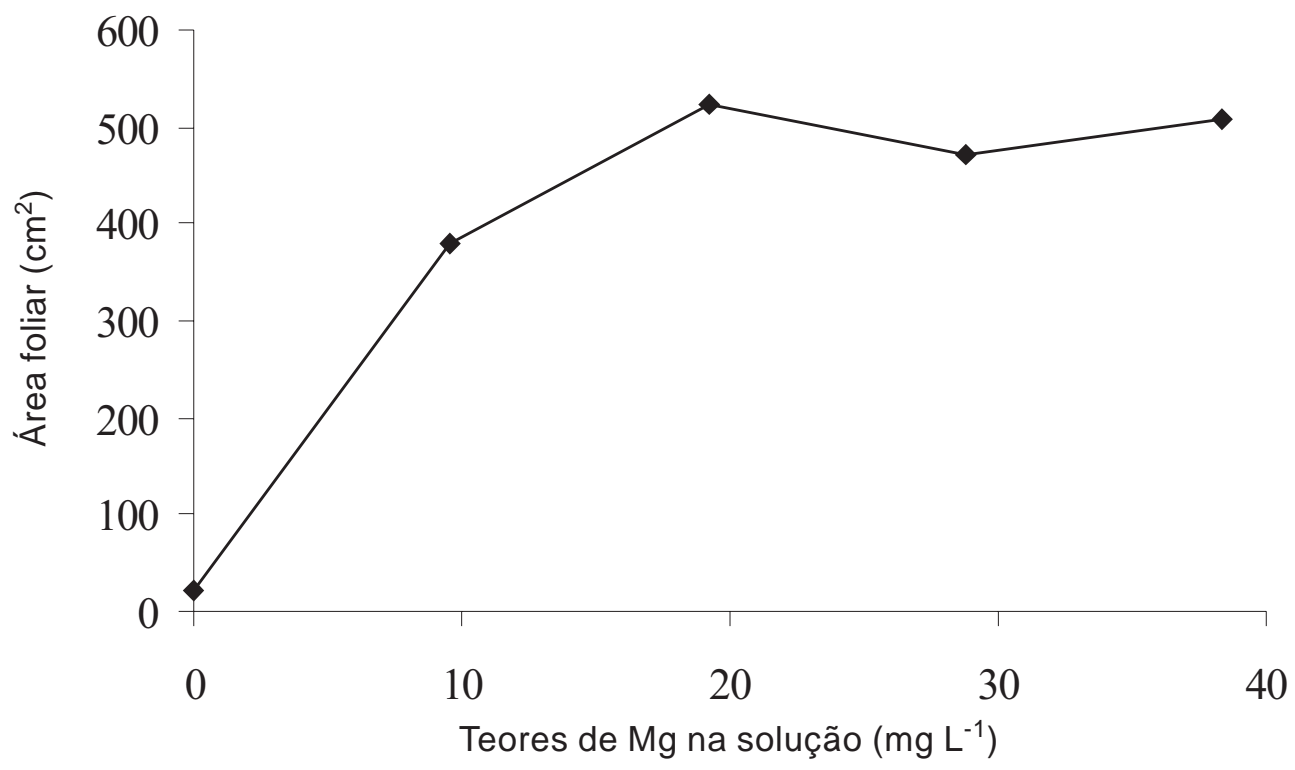

Figura 2. Área foliar de Heteranthera reniformis sob o efeito de diferentes teores de magnésio na solução nutritiva. Botucatu (SP), 2004.

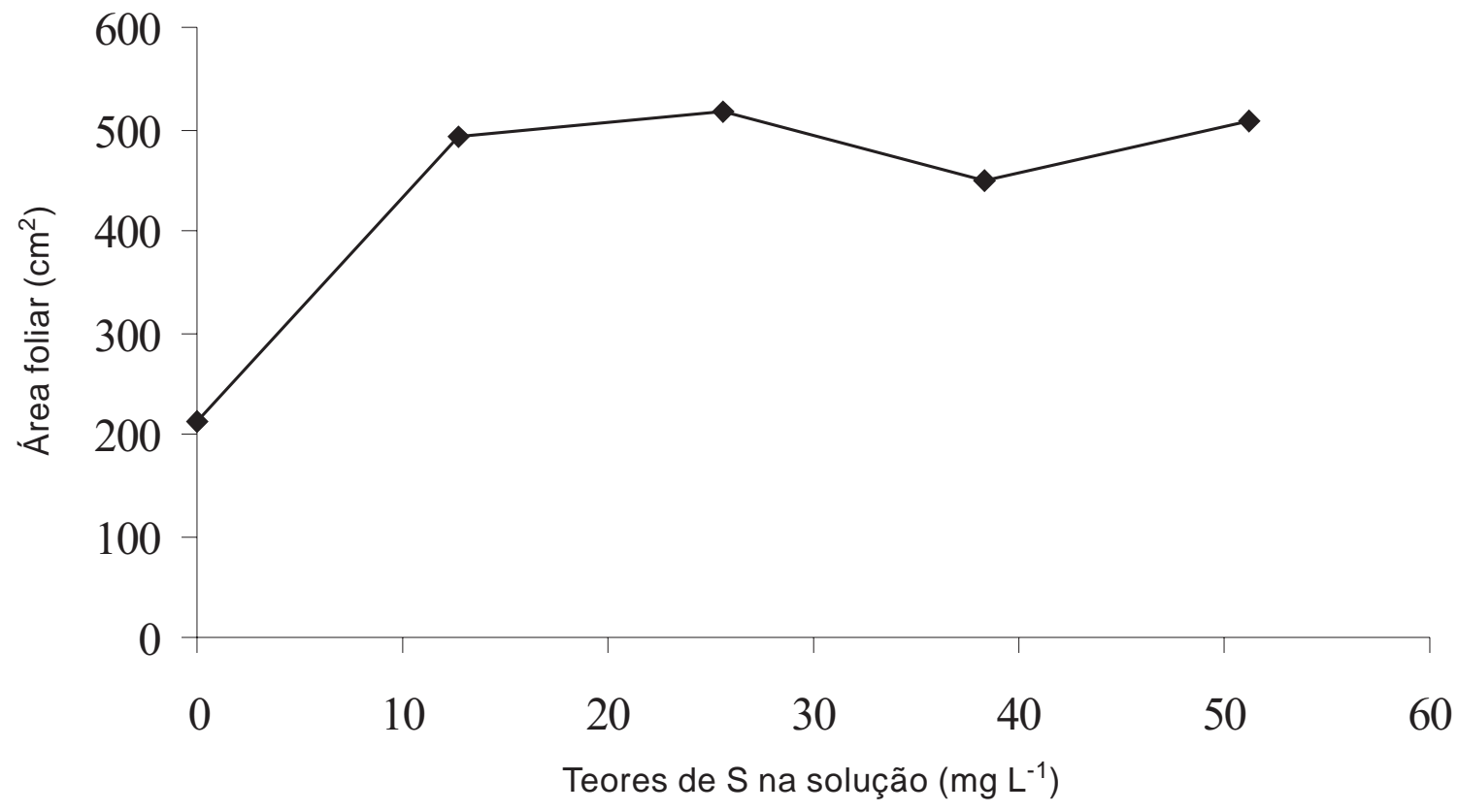

Figura 3. Área foliar de Heteranthera reniformis sob o efeito de diferentes teores de enxofre na solução nutritiva. Botucatu (SP), 2004. 


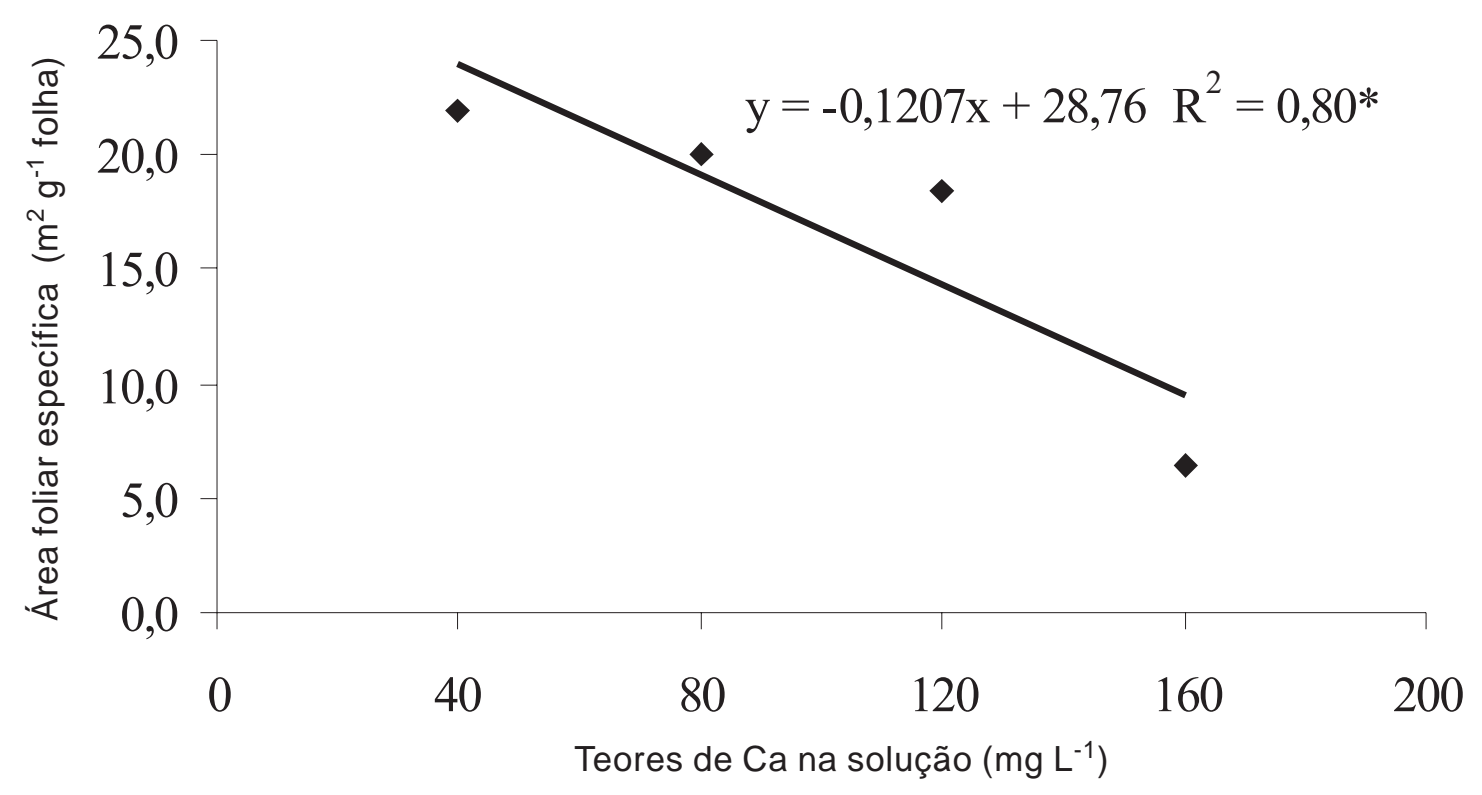

Figura 4. Área foliar específica de Heteranthera reniformis sob o efeito de diferentes teores de cálcio na solução nutritiva. Botucatu (SP), 2004.

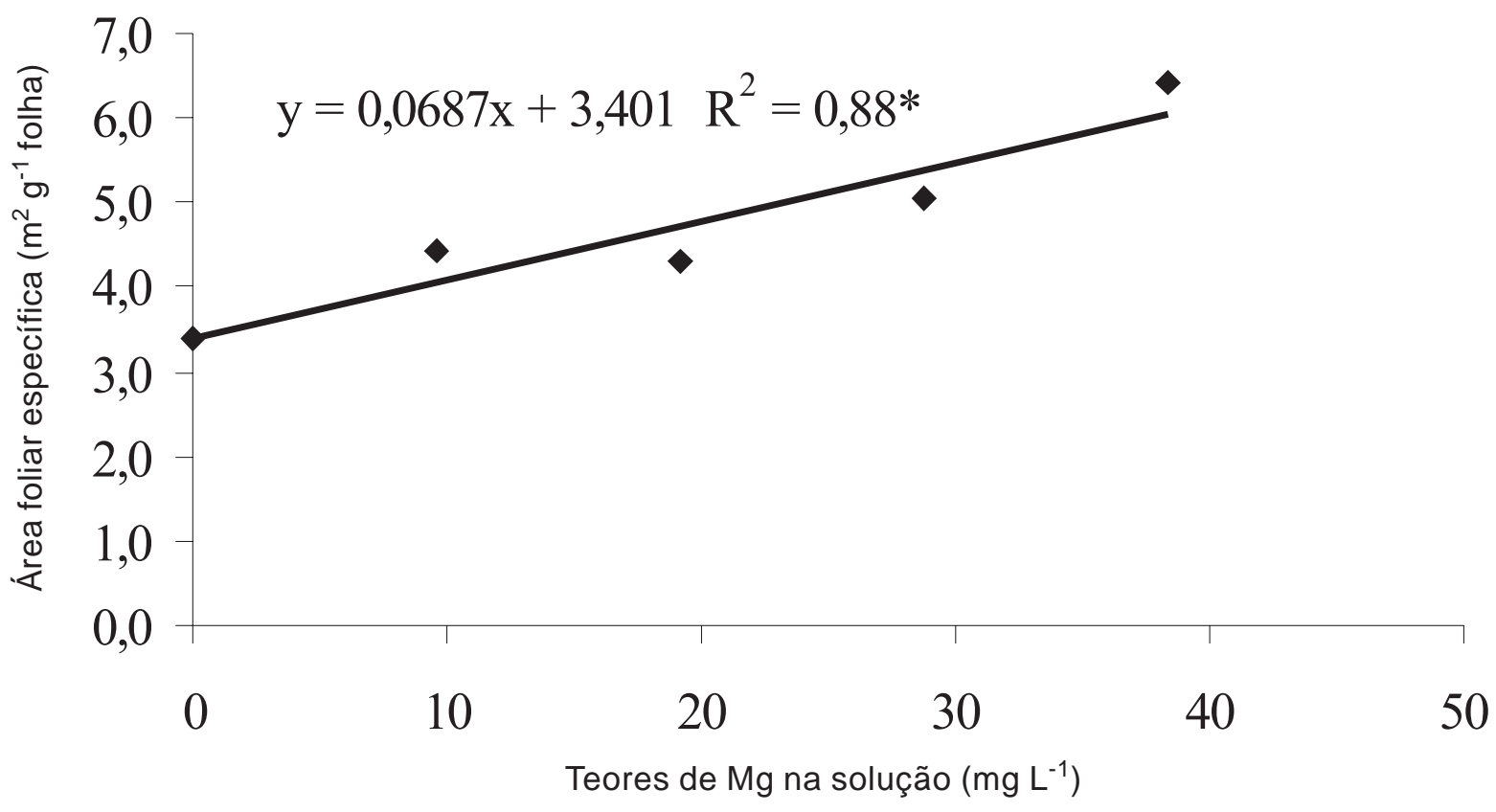

Figura 5. Área foliar específica de Heteranthera reniformis sob o efeito de diferentes teores de magnésio na solução nutritiva. Botucatu (SP), 2004. 


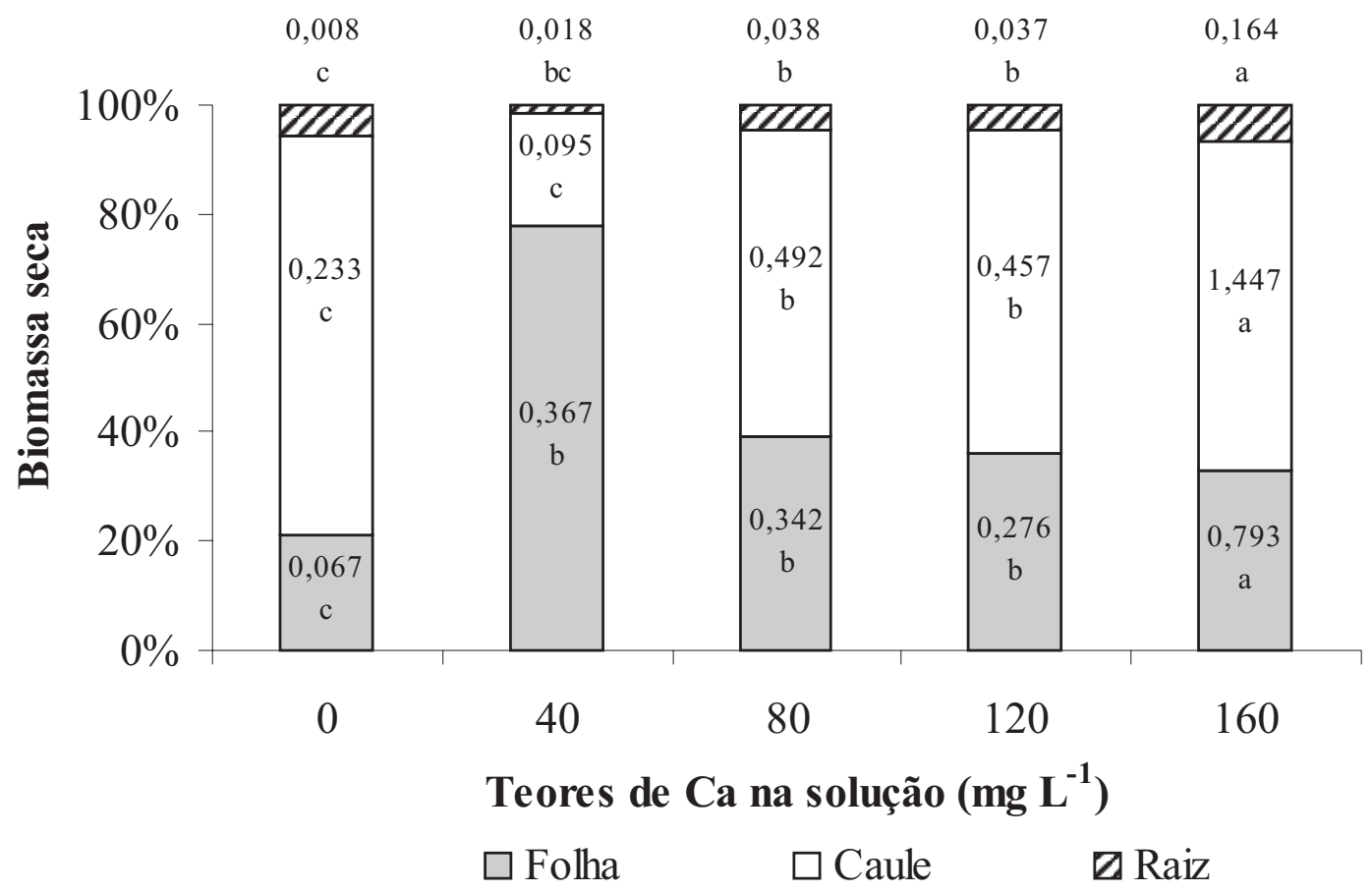

Figura 6. Alocação de biomassa seca apresentada em porcentagem no gráfico e os respectivos valores (g planta-1) em Heteranthera reniformis sob o efeito de diferentes teores de cálcio na solução nutritiva. Botucatu (SP), 2004. Médias seguidas de mesma letra não diferem estatisticamente a 5\% de probabilidade pelo teste de Tukey.

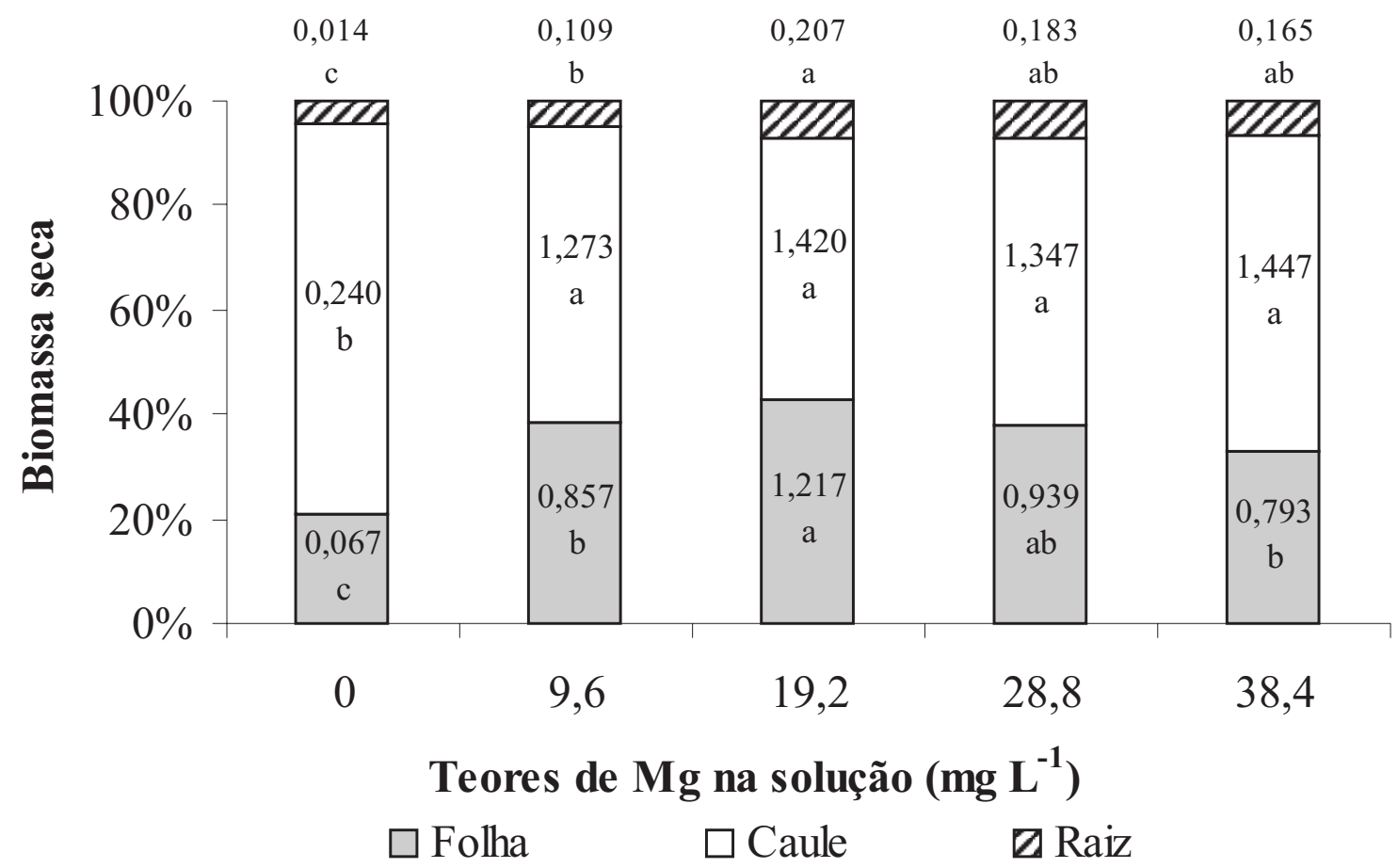

Figura 7. Alocação de biomassa seca apresentada em porcentagem no gráfico e os respectivos valores $\left(\mathrm{g}\right.$ planta $\left.{ }^{-1}\right)$ em Heteranthera reniformis sob o efeito de diferentes teores de magnésio na solução nutritiva. Botucatu (SP), 2004. Médias seguidas de mesma letra não diferem estatisticamente a 5\% de probabilidade pelo teste de Tukey. 


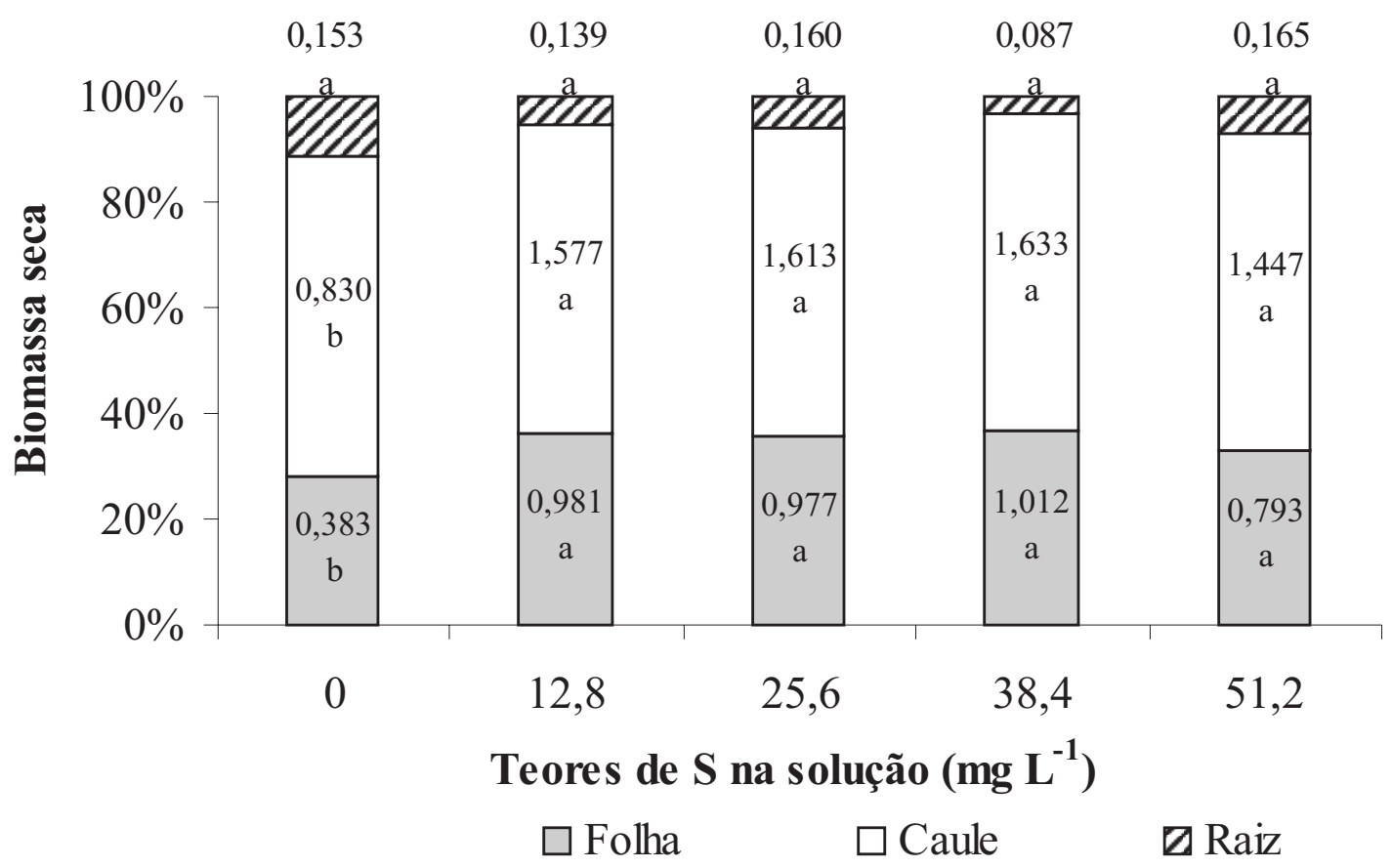

Figura 8. Alocação de biomassa seca apresentada em porcentagem no gráfico e os respectivos valores (g planta $\left.{ }^{-1}\right)$ em Heteranthera reniformis sob o efeito de diferentes teores de enxofre na solução nutritiva. Botucatu (SP), 2004. Médias seguidas de mesma letra não diferem estatisticamente a 5\% de probabilidade pelo teste de Tukey.

De maneira geral, observou-se que a deficiência de enxofre afetou o desenvolvimento da parte aérea, uma vez que, a planta estava com maior proporção de raízes e também outros sintomas de deficiência em relação aos outros teores na solução como redução na área foliar, biomassa da parte aérea, teor de $\mathrm{S}$ na folha e coloração pálida na folha. Esse comportamento corrobora os sintomas de deficiência em plantas, descritos na literatura, e que relata a redução no desenvolvimento das plantas resultante de folhas menores e principalmente o crescimento de caules mais afetado do que o de raízes (BERGMANN, 1992).

A maior concentração de Ca obtida na folha foi de $56,6 \mathrm{~g} \mathrm{~kg}^{-1}$ com o teor de $160 \mathrm{mg} \mathrm{L}^{-1}$ na solução nutritiva (Figura 9). Esse teor de Ca na folha pode ser considerado alto entre plantas aquáticas, o qual permite inferir a hipótese de tolerância a metais pesados como ocorre com o gênero Typha em que houve tolerância a $\mathrm{Zn}, \mathrm{Pb}, \mathrm{Cd}, \mathrm{Cu}$ e $\mathrm{Ni}$, uma vez que o Ca constitui a estrutura de compostos como oxalatos e pectatos de Ca presente na parede celular que reduz a translocação desses metais resultante da formação de complexos insolúveis (Olivares et al., 2002; BENNETT, 1996). Verificou-se ainda, que a absorção de Ca na folha possui tendência linear e positiva com o aumento da concentração de cálcio. A translocação de
Ca da biomassa de caules para as folhas foi observada a partir de $80 \mathrm{mg} \mathrm{L}^{-1}$. As raízes podem ser consideradas como o reservatório de Ca na planta, uma vez que houve maior teor desse nutriente nas maiores concentrações, provavelmente, em decorrência da baixa mobilidade do Ca na planta (RAIJ, 1991). O teor de Ca considerado ótimo para o crescimento, verificado em espécies da mesma família de $H$. reniformis como E. crassipes, foi de $30 \mathrm{mg} \mathrm{L}^{-1}$ (SINGH et al., 1984). Portanto, a concentração de $40 \mathrm{mg}$ $\mathrm{L}^{-1}$ de Ca que promoveu o incremento de biomassa e área foliar pode ser considerada mais favorável ao desenvolvimento da espécie.

Quanto aos teores de $\mathrm{Mg}$ na planta, o comportamento nos órgãos da parte aérea foi semelhante, embora com maior teor no caule, entre 20 e $30 \mathrm{mg} \mathrm{L}^{-1}$, os teores na folha não diferem entre os diferentes teores testados na solução (Figura 10).

Os teores de enxofre nas folhas e nos caules aumentaram com a concentração de $S$, enquanto o teor nas raízes foi reduzido nas concentrações entre 12,8 e $38,4 \mathrm{mg} \mathrm{L}^{-1}$ (Figura 11). Nessas condições, provavelmente, o $\mathrm{S}$ foi translocado para a parte aérea, devido a esse elemento ter alta mobilidade na planta (MARSCHNER, 1986). 


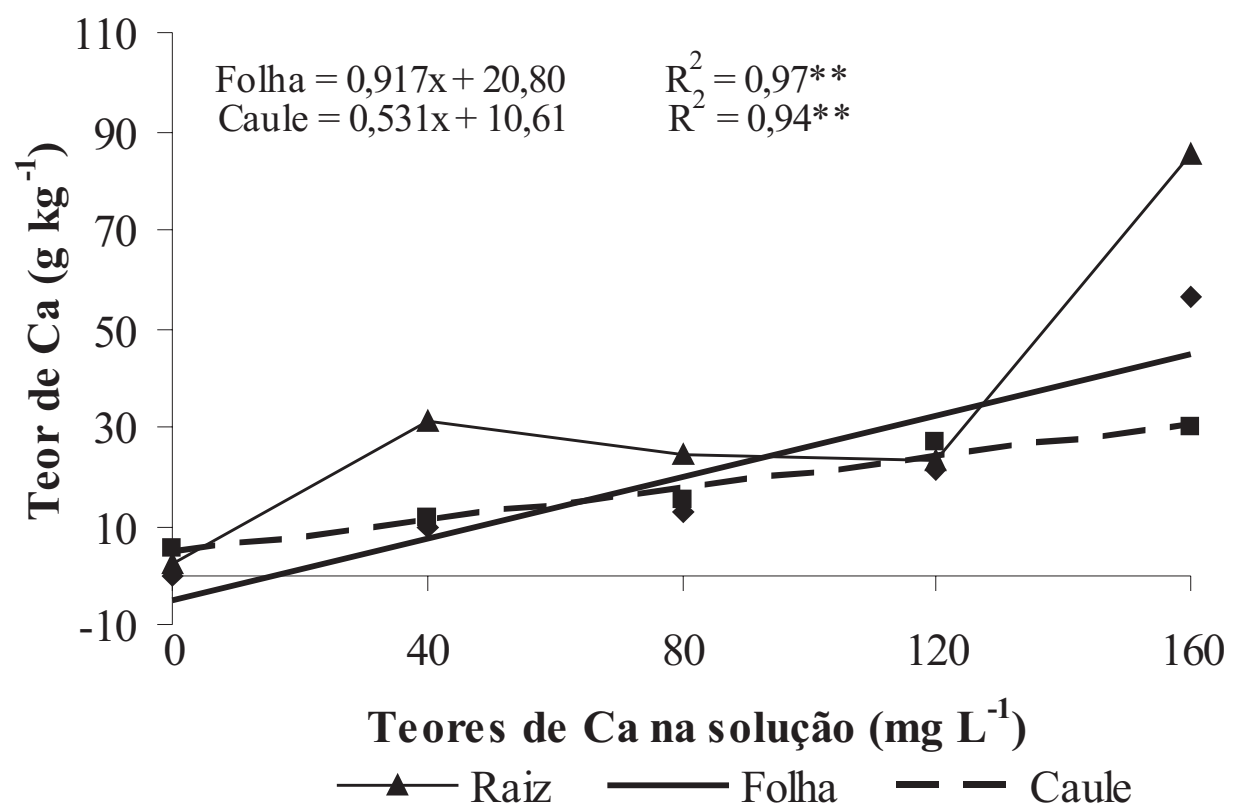

Figura 9. Alocação de cálcio em Heteranthera reniformis sob o efeito de diferentes teores de cálcio na solução nutritiva. Botucatu (SP), 2004.

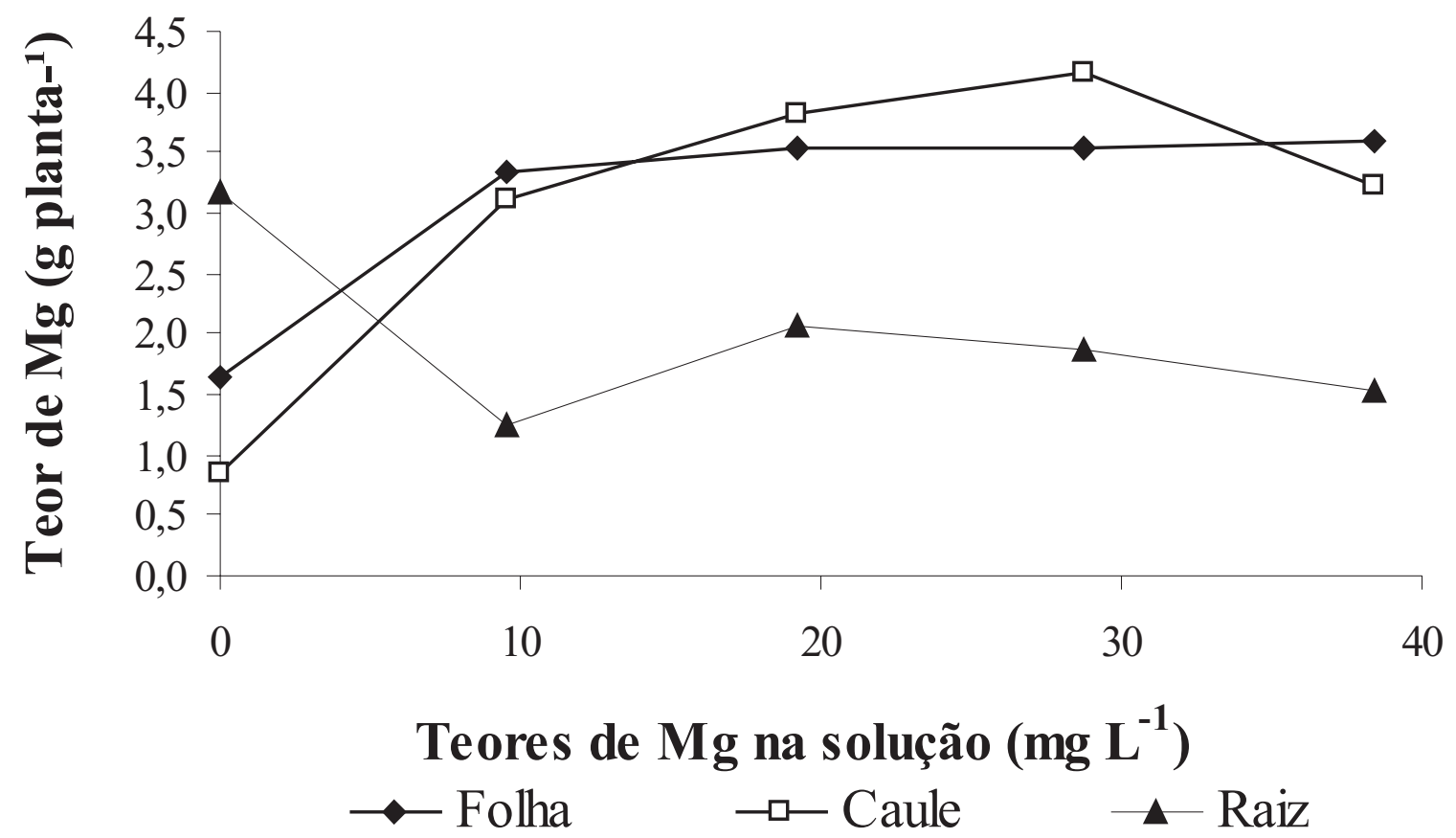

Figura 10. Alocação de magnésio em Heteranthera reniformis sob o efeito de diferentes teores de magnésio na solução nutritiva. Botucatu (SP), 2004. 


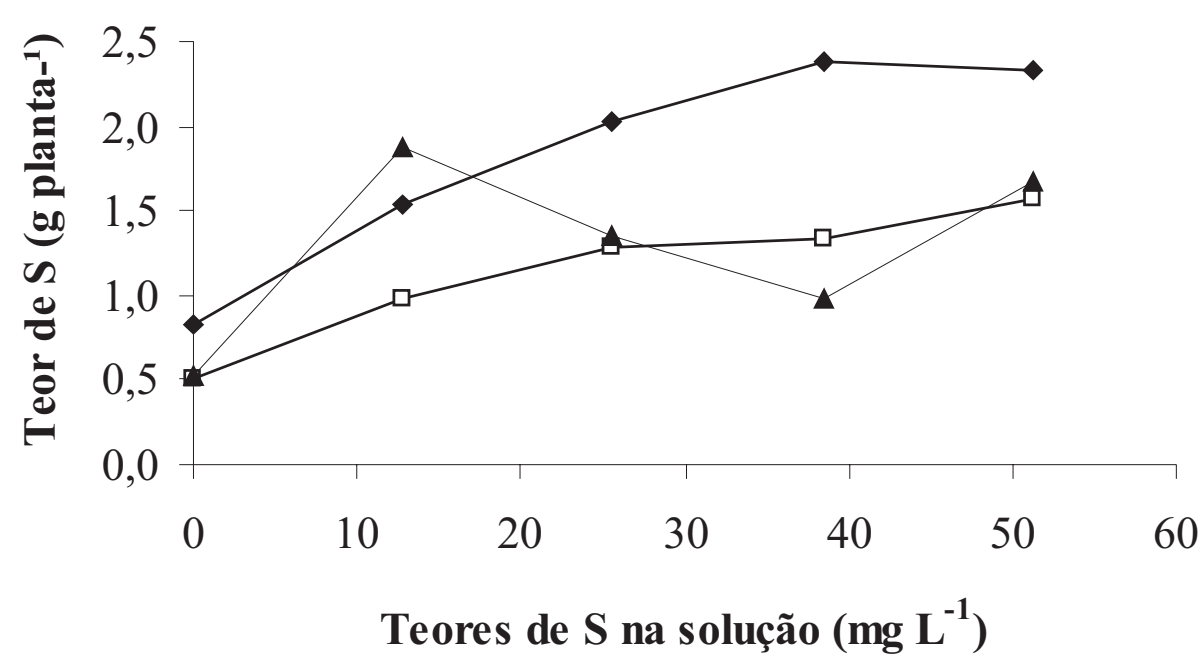

$\rightarrow$ Folha $\quad \rightarrow-$ Caule $\quad \longrightarrow$ Raiz

Figura 11. Alocação de enxofre em Heteranthera reniformis sob o efeito de diferentes teores de enxofre na solução nutritiva. Botucatu (SP), 2004.

\section{CONCLUSÃO}

A ausência de Ca e $\mathrm{Mg}$ afetou o crescimento de $H$. reniformis, ocorrendo redução significativa na área foliar e produção de biomassa. Em H. reniformis, observou-se potencial em absorver $\mathrm{Ca}$, sendo encontrado os maiores teores na raiz.

\section{AGRADECIMENTOS}

Os autores agradecem ao CNPq, pelo apoio financeiro, e à Faculdade de Ciências Agronômicas / UNESP, pela estrutura oferecida e cooperação dos funcionários na realização deste trabalho.

\section{REFERÊNCIAS}

BARRAT-SEGRETAIN, M. H. Biomass allocation in three macrophyte species in relation to the disturbance level of their habitat. Freshwater Biology, Oxford, v. 46, p. 935945, 2001.

BENNETT, W. F. Nutrient deficiencies \& toxicities in crop plants. 3.ed. St. Paul: APS Press, Texas Tech University, 1996. 202 p.

BERGMANN W. Nutritional disorders plants: development, visual and analytical diagnosis. New York: Bonis Artibus, 1992. 735 p.

ESTEVES, F. de A. Fundamentos de Limnologia. 2 ed. Rio de Janeiro: Interciência, 1998, 602 p.
FERRERO, A. Prediction of Heteranthera reniformis competition with flooded rice using day-degrees. Weed Research, Oxford, v. 36, p. 197-201,1996.

KISSMANN, K.G; GROTH, D. Plantas infestantes e nocivas. 2.ed. São Paulo: Basf , 1997. Tomo I, 825 p.

MALAVOLTA, E.; VITTI, G.C.; OLIVEIRA, S. A. Avaliação do estado nutricional de plantas: princípios e aplicações. 2. ed. Piracicaba: Potafós, 1989. 319 p.

MARSCHNER, H. Mineral nutrition of higher plants. 1.ed. San Diego: Academic Press, 1986. 674 p.

MENDES, J. A. Distribuição espacial, fenologia e compartimentação de três espécies de Qualea (Vochysiaceae) na Reserva Biológica de Mogi-Guaçu, SP. 1996. 201 f. Tese (Doutorado) - Instituto de Biociências, Rio Claro.

NICHOLS, S.A.; BUCHAN, A.J. Use of native macrophytes as indicators of sustable eurasian watermilfoil habitat in Winconsin lakes. Journal of Aquatic Plant Management, Clermont, v. 35, p. 21-24, 1997.

OLIVARES, E.; VIZCAÍNO, D.; GAMBOA, A. Mineral nutrition of three aquatic emergent macrophytes in a managed wetland in Venezuela. Journal of Plant Nutrition, New York, v. 25 n. 3, p. $475-496,2002$

OLIVEIRA, J.A. de; CAMBRAIA, J.;CANO, M.A.O.; JORDÃO, C.P. Absorção e acúmulo de cádmio e seus efeitos sobre o crescimento relativo de plantas de aguapé e salvínia. Revista Brasileira de Fisiologia Vegetal, Viçosa, v. 13, n. 3, p. 329-341, 2001.

RAIJ, B. V. Fertilidade do solo e adubação. São Paulo, Piracicaba: Agronômica Ceres/POTAFÓS, 1991. 343 p. 
SAHA, S.; JANA, B.B. Fish-macrophyte association as a lowcost strategy for wastewater reclamation. Ecological Engineering, Oxford, v. 21, p. 21-41, 2003.

SARRUGE, J.R. Soluções nutritivas. Summa Phytopathologica, Piracicaba, v.1, n.3, p. 231-233, 1975.

SCHIPPERS, P.; OLFF, H. Biomass partitioning, architecture and turnover of six herbaceous species from habitats with different nutrient supply. Plant Ecology, Dordrecht, v. 149 p. 219-231, 2000.

SINGH, H.D., NAG, B., SARMA, A.K. AND BARUAH, J.N. Nutrient control of water hyacinth growth and productivity. In: THYAGARAJAN, G. (Ed.). INTERNATIONAL CONFERENCE ON WATER HYACINTH, 1984, Nairobi. Proceedings... Nairobi: UNEP, 1984. p. 243-263.

SO, L.M.; CHU, L.M.; WONG, P.K. Microbial enhancement of $\mathrm{Cu}^{2+}$ removal capacity of Eichhornia crassipes (Mart.). Chemosphere, Oxford, v. 52, p. 1499-1503, 2003.
THOMAZ, S.M.; BINI, L.M. Ecologia e manejo de macrófitas aquáticas em reservatórios. Acta Limnológica Brasileira, São Carlos, v. 10, n 1 p. 103-116, 1998.

VASCONCELOS, T.; TAVARES, M.; GASPAR, N. Aquatic plants in the rice fields of the Tagus Valley, Portugal. Hidrobiologia, Bucareste, v. 415, p. 59-65, 1999.

VESCOVI, F.D.; TANO, F.; SPARACINO, R.; FERRO, R.; RIVA, N. Effects of time and duration of competition between rice (Oriza sativa L.) and Heteranthera reniformis Ruiz \& Pav. In: INTERNATIONAL SYMPOSIUM ON CROP PROTECTION, 61., 1996, Gent. Abstract...Gent: Universiteit Gent, 1996. p. 1123-1128.

WETZEL, R.G. Limnologia. 2.ed. Lisboa: Fundação Calouste Gulbenkian, 1993. 915 p. 